\title{
Evidence of near-field laser ablation inductively coupled plasma mass spectrometry (NF-LA-ICP-MS) at nanometre scale for elemental and isotopic analysis on gels and biological samples $\dagger$
}

\author{
J. Sabine Becker, ${ }^{a}$ André Gorbunoff, ${ }^{b}$ Miroslav Zoriy, ${ }^{a}$ Andrei $\operatorname{Izmer}^{a}$ and \\ Markus Kayser ${ }^{c}$
}

Received 10th October 2005, Accepted 7th November 2005

First published as an Advance Article on the web 25th November 2005

DOI: $10.1039 / \mathrm{b514401a}$

Laser ablation inductively coupled plasma mass spectrometry (LA-ICP-MS) has been established as a powerful surface analytical method for local elemental analysis on metallic, ceramic, geological or biological sample surfaces. Here we show a new way of nanometre scale analysis of elements on sample surfaces by near-field LA-ICP-MS (NF-LA-ICP-MS). This technique uses the near-field enhancement effect on the tip of a thin silver needle in a laser beam (Nd:YAG laser, wavelength $532 \mathrm{~nm}$ ) on the sample surface. The thin silver needle was etched electrolytically in an electrochemical cell using a droplet of citric acid as electrolyte. For nanolocal analysis by NF-LAICP-MS on soft matter (e.g., on 2-D gels and biological samples) a small volume transparent laser ablation chamber was constructed and coupled to a double-focusing sector field inductively coupled plasma mass spectrometer (ICP-MS). A small amount of soft sample material is ablated at atmospheric pressure by a single laser shot in the near-field of the silver tip in the defocused $\mathrm{Nd}$ :YAG laser beam. The ablated material is transported with argon as carrier gas into the inductively coupled plasma (ICP) ion source of the sensitive double-focusing sector field mass spectrometer with reverse Nier-Johnson geometry. By single-shot analysis on 2-D gels and biological surfaces doped with uranium in the $\mu \mathrm{g} \mathrm{g}^{-1}$ range using NF-LA-ICP-MS an enhancement of ion intensities of transient signals in comparison with the background signal of up to factor 60 was observed. In gels doped with isotopically enriched ${ }^{65} \mathrm{Cu}$ and ${ }^{67} \mathrm{Zn}$ spikes by NF-LA-ICP-MS (single shot analysis) ion intensities up to the $n \times 10^{5} \mathrm{cps}$ range and isotope ratios $\left({ }^{235} \mathrm{U} /{ }^{238} \mathrm{U},{ }^{65} \mathrm{Cu} /{ }^{63} \mathrm{Cu}\right.$ and $\left.{ }^{67} \mathrm{Zn} /{ }^{64} \mathrm{Zn}\right)$ were measured at a lateral resolution in the nanometre scale. Using the near-field effect in LA-ICP-MS, it was demonstrated that nanolocal analysis is possible in single-shot measurements of elements on biological samples and on a gel surface with spatial resolution at the hundreds of nanometres range. This first experiment on near-field LA-ICP-MS opens up a new, challenging path for future applications in nanoimaging of elements in life science, biology and medicine, e.g., for analyses of single cells, cell organelles or biological structures at nanometre range in order to detect neurodegenerative diseases, but also in material science, nanotechnologies and nanoelectronics.

\section{Introduction}

Surface analytical techniques with lateral resolution on the nanometre scale are indispensable for nanoimaging in many fields of the life sciences, medicine, biology, engineering and materials research, e.g., for the characterization of nanoelectronics with respect to trace impurities. ${ }^{1-4}$ Nanoimaging - that is, elemental, chemical and structural analysis on the nanometre scale - is required today especially for the quantitative analysis of elemental distribution on the nanometre scale in

\footnotetext{
${ }^{a}$ Central Division of Analytical Chemistry, Research Centre Juelich, D-52425 Juelich, Germany

${ }^{b}$ University of Applied Sciences Dresden, Friedrich-List-Platz 1, D-01069 Dresden, Germany

${ }^{c}$ Bruker Daltonik, D-28359 Bremen, Germany

$\dagger$ Electronic supplementary information (ESI) available: theory of near-field optical enhancement. See DOI: 10.1039/b514401a
}

single cells or cell organelles for studies in modern medicine and would help to clear up a multitude of relevant open questions in the detection and treatment of diseases (e.g., neurodegenerative diseases such as Parkinson's or Alzheimer's, where phosphorus and metal ions play an important role). ${ }^{5}$

Microscopic analytical techniques such as scanning tunnelling microscopy (STM), atomic force microscopy (AFM) ${ }^{6}$ and scanning near-field optical microscopy (SNOM) ${ }^{1,7-9}$ have been developed for the investigation of specimens with lateral resolution in the nanometre range. In STM or AFM, a sharp tip is raster-scanned across the surface to map the topography. A surface-enhanced Raman scattering (SERS) based nanoimaging probe is capable of chemical imaging with spatial resolution on the nanometre scale. ${ }^{3}$ The probes in SNOM and SERS consist mostly of an etched tapered coherent optical fibre that has been coated with a metallic layer. An analogous near-field optical fibre probe coated with aluminium (SNOM 
tip) was applied in the atmospheric pressure laser ablation of organic compounds combined with quadrupole-based mass spectrometry in Zenobi's group. ${ }^{2}$ Laser ablation on the surface of an anthracene crystal and bis(phenyl- $N, N$-diethyltriazene) was achieved using pulsed laser irradiation with a Nd:YAG laser at a wavelength of $355 \mathrm{~nm}$ coupled to the back end of SNOM tip. This particular tip had $170 \mathrm{~nm}$ diameter aperture, creating laser ablation craters with about the same diameter. ${ }^{2}$ As a nanosampling interface for the introduction of atmospheric laser ablated organic material in the high vacuum of an electron impact ion source of the quadrupole mass spectrometer, a heated stainless steel capillary was applied. The authors demonstrated on bis(phenyl- $N, N$-diethyltriazene) three laser ablated craters with a spatial resolution of about $200 \mathrm{~nm}$ and a depth of $20 \mathrm{~nm}^{2}$

None of these analytical techniques with high spatial resolution is able to perform a quantitative determination of trace elements.

As a surface analytical technique, secondary ion mass spectrometry (SIMS), ${ }^{10,11}$ for example with a gallium liquid metal primary ion source, possesses multielemental capability and allows distribution analysis of elements in small areas of the sample surface (some hundred $\mu \mathrm{m} \times$ some hundred $\mu \mathrm{m}$ ) with lateral resolution down to $50 \mathrm{~nm} .{ }^{12}$ However, the possibility of quantifying measured ion intensities in SIMS in a similar way to other solid state mass spectrometric techniques (such as glow discharge mass spectrometry-GDMS, spark source mass spectrometry-SSMS, or laser ablation inductively coupled plasma mass spectrometry) via relative sensitivity factors is very difficult if no suitable matrix-matched reference material with known analyte concentrations is available. In addition, because of a huge matrix effect of up to six orders of magnitude in SIMS (other solid mass spectrometric techniques possess significantly smaller matrix effects) a quantification of analytical results is often impossible due to the lack of standard reference materials. Other surface analytical techniques with lateral resolution in the nanometre range, such as soft X-ray microscopy at a spatial resolution better than $15 \mathrm{~nm},{ }^{4}$ Auger electron spectroscopy (AES), electron energy loss spectrometry (EELS) or secondary neutral mass spectrometry (SNMS), are not sensitive enough for the determination of trace element concentration and also have difficulties in analysing non-conducting materials and problems with the quantification of element distribution. ${ }^{13}$

Laser ablation inductively coupled plasma mass spectrometry (LA-ICP-MS) has been established as a promising powerful and sensitive multielement analytical technique for the quantitative determination of trace elements in quite different materials such as biological, ${ }^{14}$ medical $^{15,16}$ and geological ${ }^{17}$ samples or high-purity materials. ${ }^{18}$ In comparison with SIMS, a larger area of interest in the $\mathrm{cm}^{2}$ range can be investigated using LA-ICP-MS, as demonstrated by quantitative imaging of copper and zinc in thin sections of human and rat brain samples for hippocampus and tumor analysis, respectively. ${ }^{15,16}$ At present, the lateral resolution of microlocal, isotope and element distribution analysis by LA-ICP-MS is possible in the low $\mu \mathrm{m}$ range. The microlocal analysis of biological tissues or cell compartments down to single cells and cell organelles (such as mitochondria), which requires a lateral resolution on the nanometre scale, would be possible by the application of near-field (NF) sampling techniques in LAICP-MS. Furthermore, the opportunities offered by NF-LAICP-MS for precise and accurate isotope ratio measurements ${ }^{19}$ can be applied to tracer experiments using high-enriched stable isotopes on biological systems and for studying isotope variation on natural samples (e.g., for age dating).

We propose the use of near-field effect in LA-ICP-MS as an atomic mass spectrometric technique, which is commercially widely available and well established using inductively coupled plasma mass spectrometry (ICP-MS) with an atmospheric pressure ion source coupled to a suitable laser ablation system (LA) for the direct analysis of solid samples. In comparison with dynamic SIMS $^{10}$ or nano-SIMS, ${ }^{20}$ NF-LA-ICP-MS would be some orders of magnitude more sensitive (in SIMS the detection limits are in the $\mathrm{ng} \mathrm{g}^{-1}$ range, ${ }^{13}$ whereas in LAICP-MS detection limits down to the $\mathrm{pg} \mathrm{g}^{-1}$ range have been measured $^{21}$ ), less expensive and would open up the possibility of quantitative determination of elements at nanometre range. Furthermore, the disadvantages of SIMS - the huge matrix effects, limits by the analysis of non-conduction materials and the disturbing high molecular and cluster ion formation - are significantly reduced in LA-ICP-MS.

The aim of our work is the development of near-field LAICP-MS proposed in a patent script by Becker et al. in $2003^{22}$ for local analysis at the nanometre scale on soft matter, such as biological tissues or two-dimensional gels, for future applications in the life sciences and in proteomics.

\section{Physical principles of near-field LA-ICP-MS}

As an alternative to the aperture SNOM-based probes in the laser ablation of organic substances developed in Zenobi's group $^{2}$ we propose the use of an approach described by Stockmann in $1989^{23}$ for the laser ablation of sample at the nanometre scale. The idea of this approach consists in the formation of radiation intensity singularities by means of very small conductive objects immersed in the light radiation field. The resulting electric (linear or non-linear) polarization of such objects causes a considerable enhancement of the radiation intensity in the region, comparable with the curvature radius of the object (near-field enhancement). Such an object can itself therefore be treated as a very small but intensive source of secondary evanescent near-field radiation, which can be much more intensive than the field of the primary beam. If this source is brought so close to the target surface that this secondary radiation cannot diverge to any great degree, it can cause local laser-induced surface effects (e.g., local desorption or ablation of sample) limited only by the object size rather than by diffraction effects. The factor of the electrical field enhancement depends, on the one hand, on the form and the material of the field-enhancing object, and on the other hand, on the wavelength and polarization of the light. This factor can theoretically reach $10^{4}$ for a probate spheroid or a long sharp needle made of silver, provided the light wavelength belongs to the green or red spectral region and its electrical vector lies parallel to the major axis of the metallic object. ${ }^{24,25}$ In experiments the needle should be positioned very close to the sample surface in the region of the optical near field, 
whereby the near field enhancement of the thin silver needle depends on the distance to the sample surface, shape and diameter of tip, the field concentration at the tip and the resonant excitation of collective electron oscillations (plasmons) in the metal. The theoretical background of the near field enhancement effect can be found in the ESI $\dagger$.

\section{Experimental}

The experimental arrangement of near-field laser ablation ICP-MS (NF-LA-ICP-MS), developed at the Research Centre Juelich, is shown in the schematic part of Fig. 1(a). For sensitive microlocal analysis on small soft sample surfaces, and to control the positioning of the silver needle on the sample surface, a small transparent laser ablation chamber of PMMA was constructed. To observe the position of the silver needle on the sample surface a video camera was installed, as shown in Fig. 1(b). The performance of this laser ablation chamber (inner diameter and height of chamber each $2 \mathrm{~cm}$ ) was tested with a frequency-doubled Nd:YAG laser (Surelite II-10, Continuum, Santa Clara) at a wavelength of $532 \mathrm{~nm}$, coupled to a double-focusing sector field ICP-MS with reverse Nier-Johnson geometry (ELEMENT 1, Thermo Electron Corporation, Bremen). If a copper foil was hit by only a single laser pulse focused on the sample surface (without the silver needle) an ion intensity for ${ }^{63} \mathrm{Cu}^{+}$of $10^{10} \mathrm{cps}$ (at laser power density of about $5 \times 10^{9} \mathrm{~W} \mathrm{~cm}^{-2}$ ) was measured mass spectrometrically using this small laser ablation chamber. In order to demonstrate the near field effect in LA-ICP-MS in all experiments presented below, the laser beam was unfocused (at laser power density of $3 \times 10^{6} \mathrm{~W} \mathrm{~cm}^{-2}$ ) whereby (without needle) only the background signals of analyte were measured. The experimental parameters (summarized in Table 1) are optimized with respect to a maximum ion intensity of ${ }^{238} \mathrm{U}^{+}$.

For NF-LA-ICP-MS experiments the thin silver needle is mounted on a stainless steel holder combined with a precise $X Y Z$ manipulator (ULTRAlign ${ }^{\text {TM }} 461$, Newport Corporation, USA) on the outside of the laser ablation chamber for fine control of the silver needle movements, as shown in Fig. 1(b). In all near-field experiments (observed with a video camera) only single shot measurements were performed. The mass spectrometric measurements of ${ }^{63} \mathrm{Cu}^{+},{ }^{65} \mathrm{Cu}^{+},{ }^{64} \mathrm{Zn}^{+},{ }^{67} \mathrm{Zn}^{+}$ and ${ }^{238} \mathrm{U}^{+}$transient signals is performed at low mass resolution $(m / \Delta m=300)$.

\section{Preparation of thin tip of silver needle}

Silver needles (from a $0.5 \mathrm{~mm} \mathrm{99.9 \%} \mathrm{Ag} \mathrm{wire)} \mathrm{were} \mathrm{etched}$ electrolytically in an electrochemical cell (at a dc voltage of $200 \mathrm{~V}$ ) using a droplet of citric acid as the electrolyte, as (a)

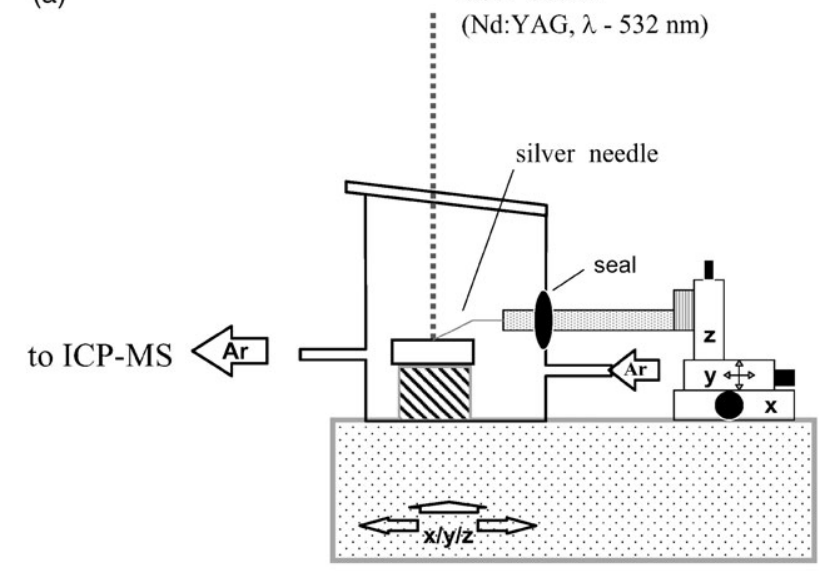

(b)

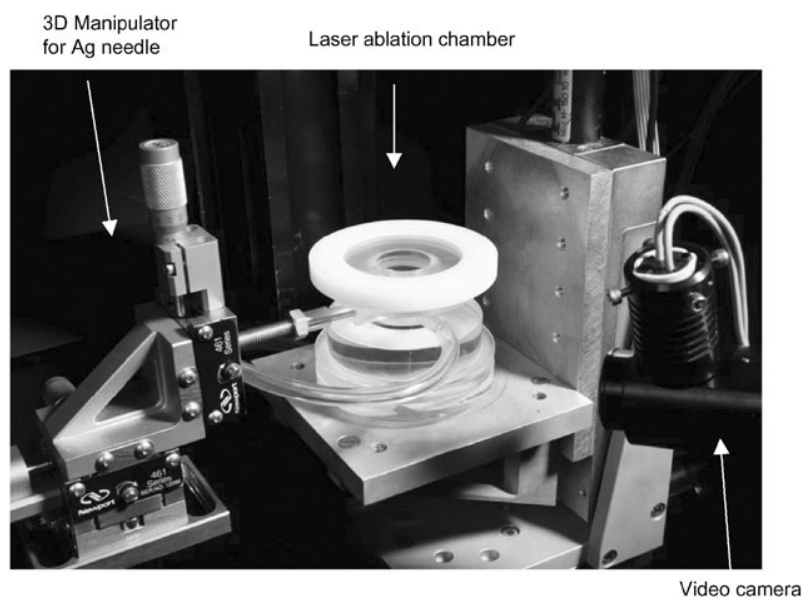

Fig. 1 (a) Experimental arrangement of near-field LA-ICP-MS. (b) Photograph of experimental arrangement with small volume laser ablation chamber (in the middle), the precise $X Y Z$ manipulator (on left) and holder for the silver needle and video camera (on right) for observation of needle position on the sample surface.

described by Gorbunoff et al. in $1993 .^{26}$ In our laboratory only $30 \mathrm{~min}$ are required for the etching of the silver needle from wire. The tip diameter at hundred nanometre range can be determined by scanning electron microscopy (SEM). The tip of the silver needle creates laser ablation craters with approximately the same diameter.

\section{Samples and sample preparation}

In order to demonstrate the figures of merit and the potential of NF-LA-ICP-MS on biological tissues, a leaf from an

Table 1 Optimized experimental parameters of NF-LA-ICP-MS

\begin{tabular}{llll}
\hline ICP-SFMS & & Laser ablation system (home made) \\
\hline Rf power & 1200 & Laser system (Nd:YAG) & Continuum \\
Cooling gas flow rate & $18 \mathrm{~L} \mathrm{~min}^{-1}$ & Wavelength & $532 \mathrm{~nm}$ \\
Auxiliary gas flow rate & $1 \mathrm{~L} \mathrm{~min}^{-1}$ & Laser power density & $3 \times 10^{6} \mathrm{~W} \mathrm{~cm} \mathrm{~cm}^{-2}$ \\
Nebulizer (carrier) gas flow rate & $1.2 \mathrm{~L} \mathrm{~min}^{-1}$ & Laser energy per pulse & $\sim 150 \mathrm{~mJ}$ \\
Mass resolution $(m / \Delta m)$ & 300 & Repetition frequency & $1 \mathrm{~Hz}$ \\
Number of runs (pass) & $150(1)$ & Spot diameter & $\sim 150 \mathrm{~nm}$ \\
Number of laser shot & 1 & Pulse length & $10 \mathrm{~ns}$ \\
\hline
\end{tabular}


Table $2{ }^{65} \mathrm{Cu} /{ }^{63} \mathrm{Cu}$ and ${ }^{67} \mathrm{Zn} /{ }^{64} \mathrm{Zn}$ and abundances of ${ }^{65} \mathrm{Cu}$ and ${ }^{67} \mathrm{Zn}$ in isotope enriched tracers and in nature

\begin{tabular}{lcc}
\hline $\begin{array}{l}\text { Isotope ratio } \\
\text { (enriched tracer) }\end{array}$ & $\begin{array}{l}\text { Tracer } \\
\text { (abundance) }\end{array}$ & $\begin{array}{l}\text { Nature } \\
\text { (abundance) }\end{array}$ \\
\hline${ }^{65} \mathrm{Cu} /{ }^{63} \mathrm{Cu}$ & 8.25 & 0.45 \\
$\left({ }^{65} \mathrm{Cu}\right)$ & $(96.4 \%)$ & $(30.8 \%)$ \\
${ }^{67} \mathrm{Zn} /{ }^{66} \mathrm{Zn}$ & 1.2 & 0.15 \\
$\left({ }^{67} \mathrm{Zn}\right)$ & $(39.8 \%)$ & $(4.1 \%)$ \\
\hline
\end{tabular}

African violet, a rose petal and a small piece of a 2-D gel used for separation of human proteins ${ }^{27}$ were doped with a uranium solution at $1000 \mu \mathrm{g} \mathrm{g} \mathrm{g}^{-1}$ overnight. For the first experiments uranium was selected as analyte due to its very high sensitivity in sector field ICP-MS. ${ }^{28}$ In further experiments parts of gels were doped overnight with an enriched ${ }^{65} \mathrm{Cu}$ and ${ }^{67} \mathrm{Zn}$ isotopic tracer (concentration in the tracer solution was several thousand $\mu \mathrm{g} \mathrm{g}^{-1}$ ). The isotopic ratios ${ }^{65} \mathrm{Cu} /{ }^{63} \mathrm{Cu}$ and ${ }^{67} \mathrm{Zn} /{ }^{64} \mathrm{Zn}$ and abundances of isotope enriched ${ }^{65} \mathrm{Cu}$ and ${ }^{67} \mathrm{Zn}$ in tracers and in nature are summarized in Table 2. Furthermore, homogeneous acrylamide gels with uranium isotope standard reference material (NIST U020, uranium concentration of $46 \mu \mathrm{g} \mathrm{g}^{-1}$ ) and natural uranium (4, 10 and $20 \mu \mathrm{g} \mathrm{g}^{-1}$ ) were prepared.

Small pieces of dried gel samples $(5 \mathrm{~mm} \times 5 \mathrm{~mm})$ doped with uranium or ${ }^{65} \mathrm{Cu}$ and ${ }^{67} \mathrm{Zn}$ isotopic enriched tracers, respectively, were fixed in the small volume laser ablation chamber of home-made laser ablation system.

The homogeneous distribution of, for example, uranium in the doped gel at the $\mu \mathrm{m}$ range was confirmed by depth profile analysis of analyte using a commercial laser ablation ICPQMS (Elan 6000, SCIEX, coupled to CETAC LSX 200) with a spatial and depth resolution at $\mu \mathrm{m}$ range.

\section{Results and discussion}

The first experiment concerned the nanolocal analysis of doped 2-D gels as soft matter which could be of relevance for future applications in screening very small protein spots with respect to an analysis of phosphorus- and metal-containing proteins. ${ }^{5,27,29} \mathrm{~A}$ small piece of the 2-D gel blank ${ }^{27}$ doped with a uranium solution overnight $\left(1000 \mu \mathrm{g} \mathrm{g}^{-1}\right)$ was investigated by NF-LA-ICP-MS. Figs. $2 a$ and $2 b$ demonstrate the position of the silver needle far away from the sample surface and on the gel surface investigated. In Fig. 2c a SEM micrograph of a silver tip after use in NF-LA-ICP-MS is shown. The tip diameter is in the several hundred nanometre range. A tip diameter at about $150 \mathrm{~nm}$ range was measured on a freshly etched silver needle by SEM before NF-LA-ICP-MS measurements (see Fig. 2d); this tip creates laser ablation craters with approximately same diameter. Smaller tip diameters and consequent better lateral resolution of NF-LA-ICP-MS at the nanometre scale range are possible.

Fig. 3 presents six single shot measurements each of the background signals (transient signals 1-6, silver needle is far away from sample surface). Also in Fig. 3 six enhanced transient ion signals (7-12, needle is positioned much closed to the sample surface) measured on gel surface doped with uranium are shown. In this experiment transient-enhanced ${ }^{238} \mathrm{U}^{+}$ion signals of high intensity (up to about $10000 \mathrm{cps}$ ) due to the near-field effect during laser ablation in a defocused laser beam in comparison with background signals of several hundred cps are observed. A maximum intensity of ${ }^{238} \mathrm{U}^{+}$ions was measured in a separate experiment (not shown in the figure) of $30000 \mathrm{cps}$ when analyzing the uranium-doped gel. This corresponds to an increase in ion intensity of a factor of 60 in a single laser shot measurement in comparison with
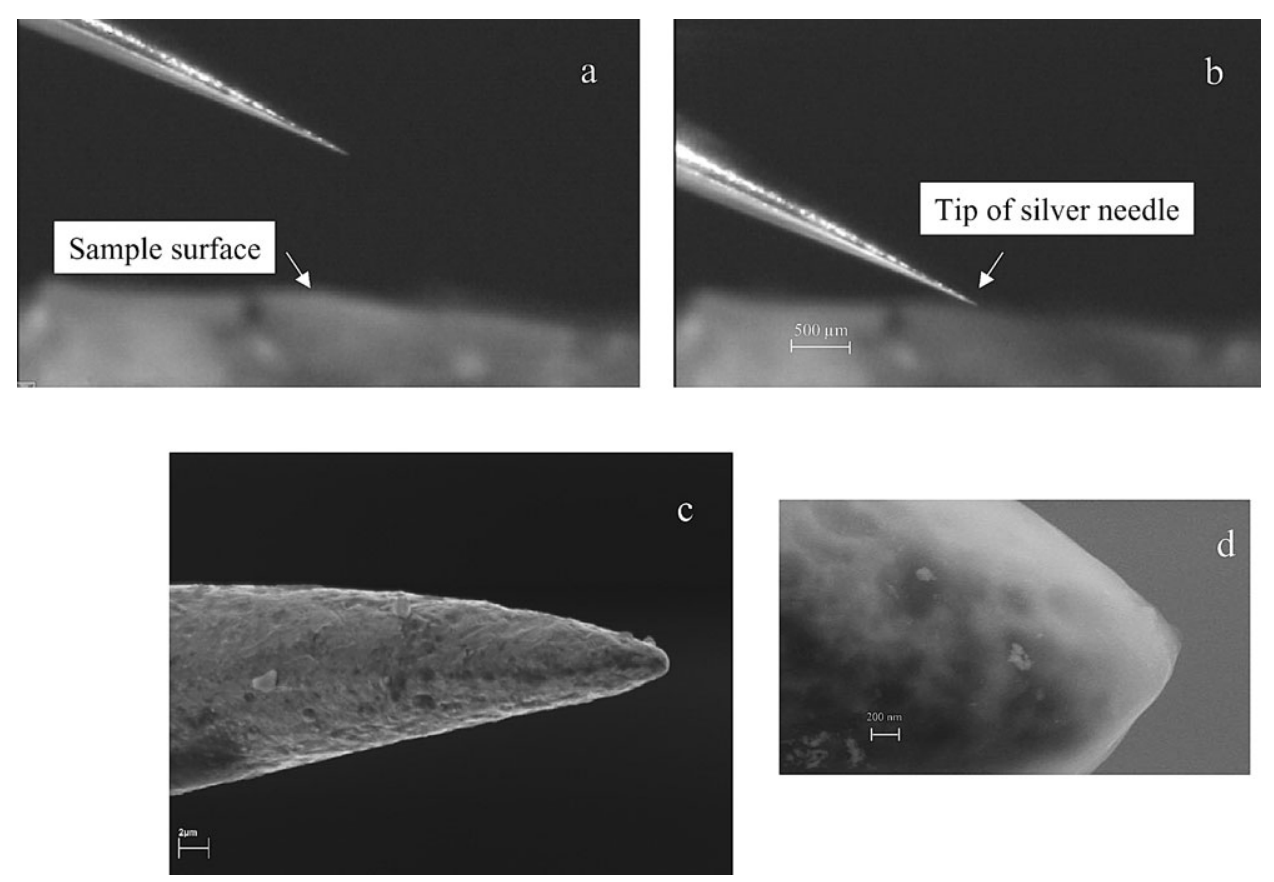

Fig. 2 Photograph of position of silver needle (a) far away from gel surface, (b) on the sample surface, and (c) and (d) SEM micrographs of a silver tip. 


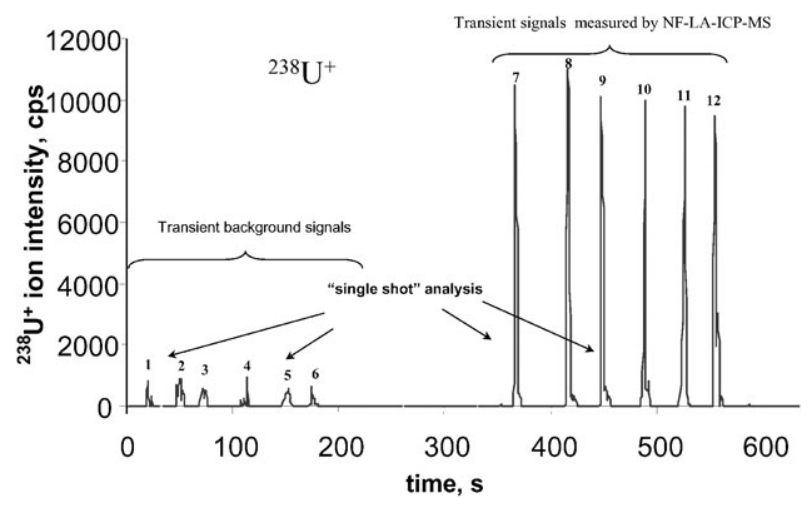

Fig. 3 Six transient ${ }^{238} \mathrm{U}^{+}$background signals (left) in defocused laser beam (needle is far away from the sample surface) and six signals measured by NF-LA-ICP-MS (needle is on the sample surface) analysing a 2-D gel doped with uranium as a function of measurement time.

transient background signals. Such significant signal enhancement is undoubtedly related to the near-field effect in LA-ICPMS. These first measurements demonstrate the great advantage of near-field laser ablation ICP-MS, with only single shot measurements during a very short time with a spatial resolution in the hundred nanometre range.

Another experiment focused on the quantification possibilities of NF-LA-ICP-MS. In Fig. 4 a transient signal of the ${ }^{238} \mathrm{U}^{+}$on the gel sample doped with the natural uranium tracer solution, with different concentrations, measured by the developed NF-LA-ICP-MS method is shown. In shots 1-4 the needle is positioned far away from the gel surface and background intensity is measured. In shots $5-13$ the needle is placed on the surface of gel samples with different uranium
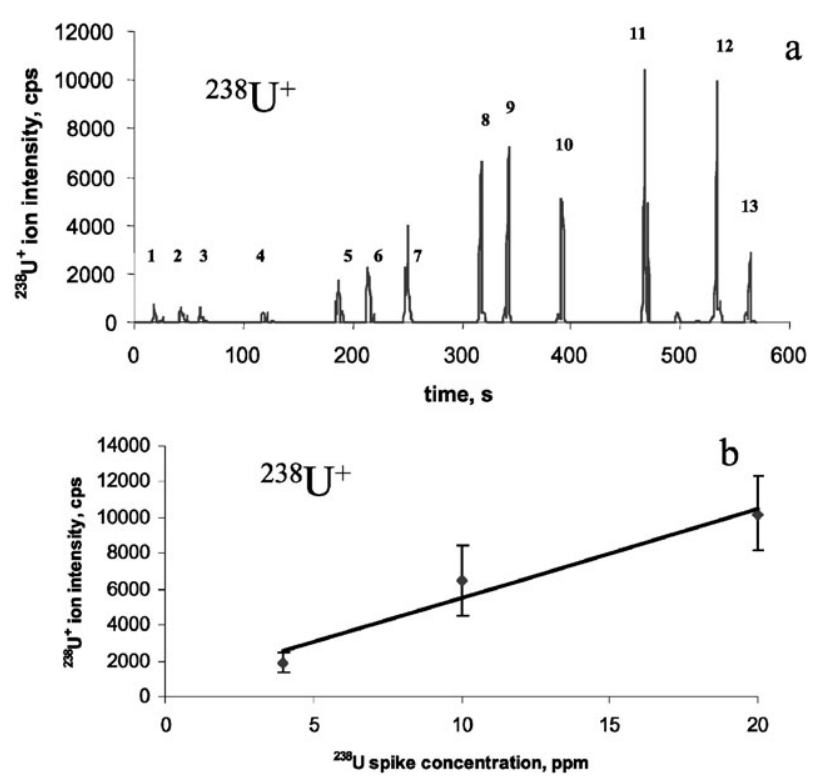

Fig. 4 a, Transient signals of ${ }^{238} \mathrm{U}^{+}$measured in gel doped with natural uranium. Transient signals 1-4: background signals; transient signals 5-7: $\mathrm{U}$ concentration $4 \mu \mathrm{g} \mathrm{g}^{-1}$; transient signals $8-10$ : $\mathrm{U}$ concentration $10 \mu \mathrm{g} \mathrm{g}^{-1}$; transient signals 11-13: $\mathrm{U}$ concentration $20 \mu \mathrm{g} \mathrm{g}^{-1}$ (spot 13: tip of silver needle was damaged). b, Calibration curve for ${ }^{238} \mathrm{U}^{+}$.

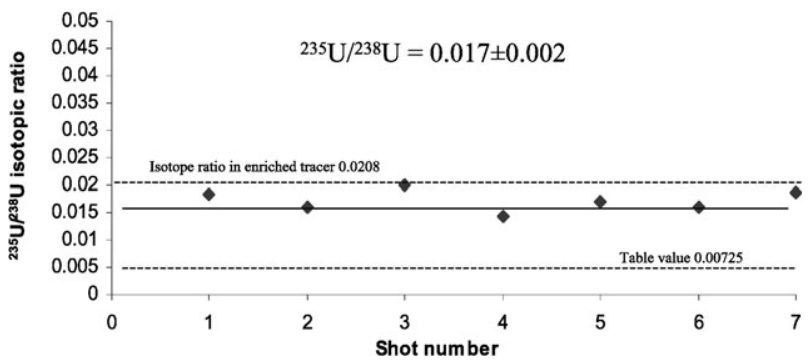

Fig. $5{ }^{235} \mathrm{U} /{ }^{238} \mathrm{U}$ isotope ratios in gel doped with NIST U20 measured by NF-LA-ICP-MS.

concentrations (transient signals 5-7: U concentration $4 \mu \mathrm{g}$ $\mathrm{g}^{-1}$; transient signals 8-10: $\mathrm{U}$ concentration $10 \mu \mathrm{g} \mathrm{g}^{-1}$; and transient signals 11-13: $\mathrm{U}$ concentration $20 \mu \mathrm{g} \mathrm{g}{ }^{-1}$ ). A calibration curve for ${ }^{238} \mathrm{U}^{+}$in gels with a correlation coefficient of 0.96 was measured by NF-LA-ICP-MS. During the laser shot 13 the tip of the silver needle was deformed, therefore the shot 13 was been not considered in the calibration curve. The detection limit for uranium determination in gel by NF-LAICP-MS (in one single laser shot) was determined in this experiment to be in the sub $\mu \mathrm{g} \mathrm{g}^{-1}$ range.

The results of ${ }^{235} \mathrm{U}^{+} p^{238} \mathrm{U}^{+}$isotope ratio measurements on a gel doped with isotope standard reference material NIST U020 are summarized in Fig. 5. The ${ }^{235} \mathrm{U}^{+} / 238 \mathrm{U}^{+}$isotope ratio (average of seven single shot measurements) was determined to be $0.017 \pm 0.002$ by NF-LA-ICP-MS measurements on the nanometre scale.

Further experiments concerned isotope ratio measurements of copper and zinc in gels doped with enriched ${ }^{65} \mathrm{Cu}$ and ${ }^{67} \mathrm{Zn}$ isotopic tracers. The transient ${ }^{65} \mathrm{Cu}^{+}$and ${ }^{67} \mathrm{Zn}^{+}$ion signals of enriched tracers measured in doped gel are shown in Figs. 6(a) and $7(a)$, respectively. Whereas in the left part of the figures background signals in the defocused Nd:YAG laser beam are measured, the transient signals with high ion intensities in the right part can be explained only as a result of the near-field enhancement effect in laser ablation. In all experiments (laser shots $8-15)$ the thin silver needle is quite close to the gel surface, whereby each transient signal corresponds to only a single laser shot measured by near-field laser ablation coupled to a sensitive double-focusing ICP mass spectrometer. Both figures for transient signals with maximum ion intensities of about $8 \times 10{ }^{5} \mathrm{cps}$ for ${ }^{65} \mathrm{Cu}^{+}$are similar. Ion intensities of ${ }^{67} \mathrm{Zn}^{+}$are about one order of magnitude lower. A serious problem in our experiments was insufficient control of the distance between the tip and sample surface. Therefore, a variation of ion intensities from laser shot to laser shot was observed. Furthermore, an inhomogeneous analyte distribution in the nanometre scale range is also possible. A significant improvement of the needle approach control is required in future experiments. The capability of ${ }^{65} \mathrm{Cu} /{ }^{63} \mathrm{Cu}$ and ${ }^{67} \mathrm{Zn} /{ }^{64} \mathrm{Zn}$ isotope ratio measurements in doped gels by NFLA-ICP-MS is demonstrated in Figs. 6(b) and 7(b): the experimental results are compared with isotope ratios in isotope enriched tracers and in nature (for IUPAC table value, ${ }^{30}$ see Table 2). The measured isotope ratios for ${ }^{65} \mathrm{Cu} /{ }^{63} \mathrm{Cu}$ and ${ }^{67} \mathrm{Zn} /{ }^{64} \mathrm{Zn}$ of 4.61 and 0.94 , respectively, in comparison with the isotope enriched tracer ratios of 8.25 and 
(a)

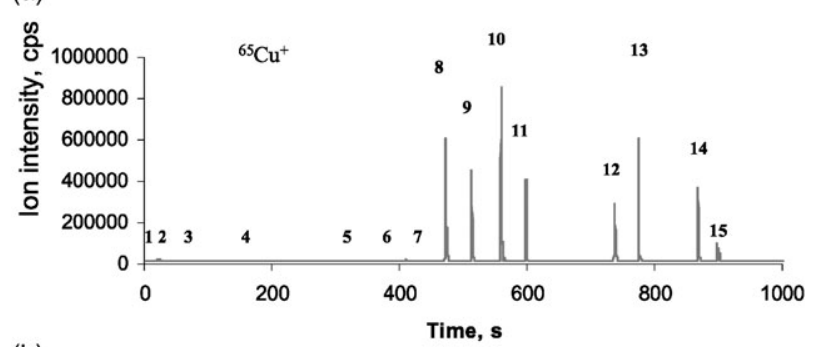

(b)

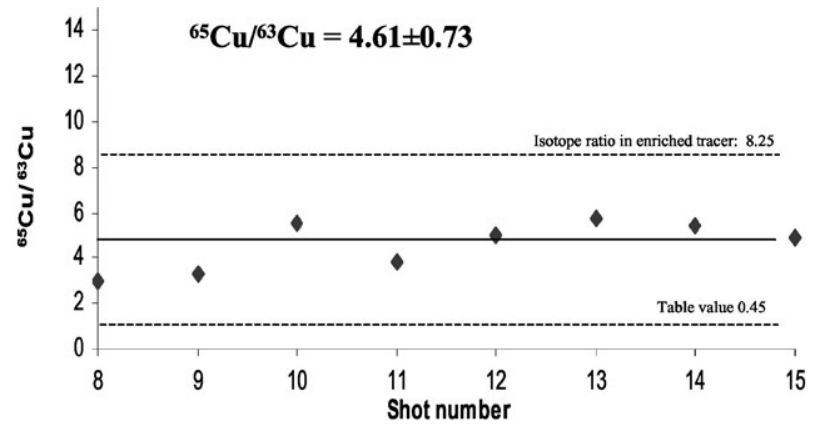

Fig. 6 (a) Transient ${ }^{65} \mathrm{Cu}^{+}$background signals in defocused laser beam (needle is far away from the sample surface) and enhanced transient signals measured by NF-LA-ICP-MS (needle is on the sample surface) analysing a gel doped with enriched ${ }^{65} \mathrm{Cu}$ isotope spike. (b) ${ }^{65} \mathrm{Cu} /{ }^{63} \mathrm{Cu}$ isotope ratios in gel doped with enriched ${ }^{65} \mathrm{Cu}$ isotope spike measured by NF-LA-ICP-MS.

1.2, respectively, demonstrate a quantification possibility via the isotope dilution technique for future application. NF-LAICP-MS can be also used to study the formation of metalcontaining proteins separated by two dimensional gel electrophoresis via isotopic-enriched tracer experiments, as described by J. Su. Becker et al. ${ }^{31}$

In another experiment, a biological sample - a small piece of a rose petal doped with uranium — was analyzed by NF-LAICP-MS. Three transient signals with ${ }^{238} \mathrm{U}^{+}$ion intensity of $15300 \mathrm{cps}, 6200 \mathrm{cps}$ and $700 \mathrm{cps}$, respectively, decreasing from laser shot to shot, were measured. The reason for the significant decrease in ion intensity from shot to shot during the NF-LA-ICP-MS measurements observed can be explained by deformation of the tip of silver needle.

Furthermore, a biological sample with a rough sample surface was investigated. Fig. 8 shows the photograph of a side view of the biological sample (leaf of an African violet with hairs on the leaf surface) together with a silver needle at a distance from the tissue surface. In the right insert the measured transient signals of ${ }^{238} \mathrm{U}^{+}$ions are drawn. If the $\mathrm{Ag}$ needle is far away from the leaf surface the defocused laser beam is fired at the sample surface. Background signals of about $500 \mathrm{cps}$ and below were measured. During NF-LA-ICPMS measurements the Ag needle is positioned directly on the biological sample surface and a significant enhancement of ${ }^{238} \mathrm{U}^{+}$ion intensity (right transient signal) was observed. Owing to the very rough sample surface of the African violet leaf with hairs (as shown in Fig. 8) and therefore quite different ablation conditions from shot to shot of the laser beam a variation of ion signals would be expected. In our
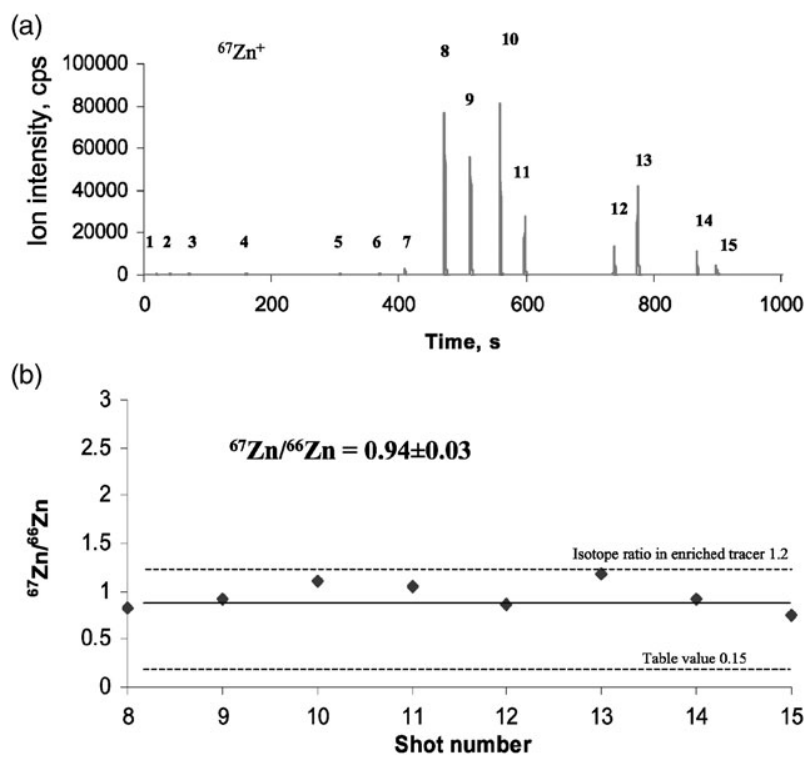

Fig. 7 (a) Transient ${ }^{67} \mathrm{Zn}^{+}$background signals in defocused laser beam (needle is far away from the sample surface) and enhanced transient signals measured by NF-LA-ICP-MS (needle is on the sample surface) analysing a gel doped with enriched ${ }^{67} \mathrm{Zn}$ isotope spike. (b) ${ }^{67} \mathrm{Zn} /{ }^{64} \mathrm{Zn}$ isotope ratios in gel doped with enriched ${ }^{67} \mathrm{Zn}$ isotope spike measured by NF-LA-ICP-MS.

experiments on the analysis of an African violet leaf doped with uranium, two enhanced transient ion signals with similar intensity (enhancement factor 30) were measured.

During all experiments we observed a decrease in near-field enhancement with increasing distance of the needle from the sample surface, which results also in a lower spatial resolution as discussed by Rasmussen and Deckert. ${ }^{2}$ The near-field enhancement effect, which depends on the tip diameter of needle, the positioning of the needle on the surface and the distance between silver tip and sample surface using an improved precise distance control, will be studied in forthcoming work.

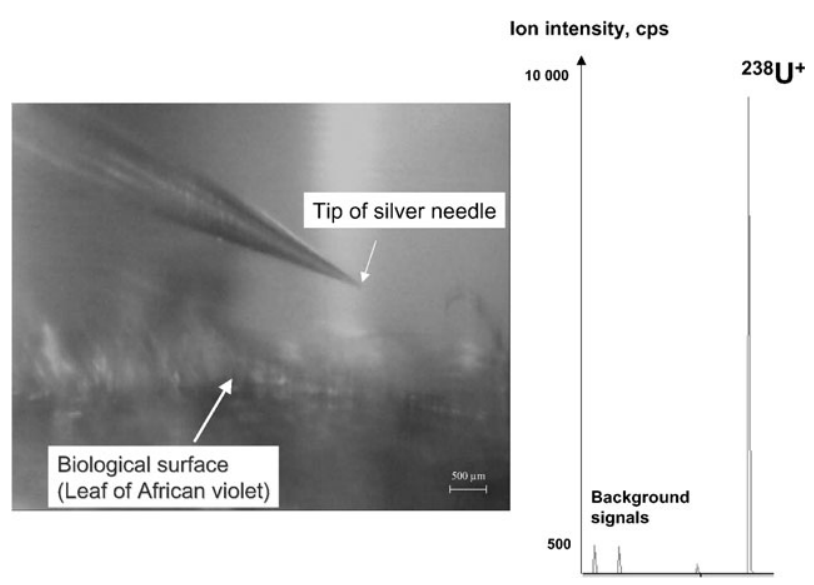

Fig. 8 Photograph of a thin silver needle and leaf surface with hairs (African violet); the right insert shows two transient ${ }^{238} \mathrm{U}^{+}$background signals and one enhanced signal measured by NF-LA-ICP-MS (the needle being on the sample). 
In comparison with the experimental arrangement in Zenobi's laboratory ${ }^{2}$ using a SNOM probe together with a nanosampling interface for the introduction of atmospheric laserablated organic material into the high vacuum of an electron impact ion source on a quadrupole mass spectrometer, our proposed experimental arrangement with the etched silver needle in laser ablation of soft matter is significantly easier when using the commercially available sensitive double-focusing sector field instrument consisting of an atmospheric pressure ICP ion source and a well designed interface to the high vacuum of the mass spectrometer. In addition, our experimental arrangement also allows a sensitive and powerful elemental analysis of difficult to determine elements (such as $\mathrm{Fe}, \mathrm{Cr}$, Se or As) due to isobaric interferences at medium and high mass resolution ( $m / \Delta m=4000$ and 12000 , respectively) of doublefocusing sector field LA-ICP-MS at the nanometre scale.

Furthermore, quantification procedures for analytical data (using certified standard reference materials, synthetic laboratory standards by external calibration or isotope dilution analysis, including the solution-based calibration established at our laboratory) and the possibility of isotope ratio measurements in NF-LA-ICP-MS as a challenging analytical tool for future application in life science will be investigated in more detail in future.

\section{Conclusions}

In our experiments, we found evidence that the near-field enhancement effect together with LA-ICP-MS when applied to soft surfaces of 2-D gels and to biological samples (leaf of African violet and rose petal) doped with uranium results in a powerful laser ablation of sample material with lateral resolution on the hundred nanometre scale. Isotope ratio measurements of uranium, copper and zinc are possible using NF-LAICP-MS at nanometre range. Using the near-field effect combined with sensitive LA-ICP-MS in single shot measurements a significant enhancement of signal intensity compared with the background signal for uranium was observed. Dependent of the tip diameter of the thin etched silver needle a lateral resolution in the $30-40 \mathrm{~nm}$ will be possible.

We anticipate that our developed NF-LA-ICP-MS will be the start of nanolocal analysis and multielemental nanoimaging in the life sciences (including proteomics), biology and medicine but also in materials science (for micro- and nanoelectronics) and other applications. For example, the nanoimaging of elements by NF-LA-ICP-MS in tissues for the detection of disease, in single cells or cell organelles will be relevant.

\section{Acknowledgements}

The authors wish to express their thanks to P. Giesen (Continuum) for providing us with the Nd:YAG laser (Surelite II20). The authors gratefully acknowledge the co-authors of the patent on NF-LA-ICP-MS ${ }^{22}$ W. Pompe, U. Krause-Buchholz and G. Rödel (TU Dresden) and M. Przybylski (University of Konstanz) for discussion of the patent idea in 2003. In addition, we acknowledge H.-J. Dietze and C. Pickhardt
(Juelich) for their valuable discussions, as well as G. Drechsler (Dresden) and H. P. Bochem (Juelich) for the SEM measurements on silver tips.

\section{References}

1 A. Rasmussen and V. Deckert, Anal. Bioanal. Chem., 2005, 381, 165.

2 R. Stöckle, P. Setz, V. Deckert, T. Lippert, A. Wokaun and R. Zenobi, Anal. Chem., 2001, 73, 1399.

3 M. E. Hankus, G. Gibson, N. Chandrasekharan and B. M. Cullum, Proc. SPIE-Int. Soc. Opt. Eng., 2004, 5588, 106.

4 W. Chao, B. D. Harteneck, J. A. Liddle, E. H. Anderson and D. T. Attwood, Nature, 2005, 435, 1210.

5 J. S. Becker, M. Zoriy, J. Su. Becker, C. Pickhardt and M. Przybylsky, J. Anal. At. Spectrom., 2004, 19, 149.

6 G. Friedbacher in Surface and thin film analysis, ed. H. J. H. Bubert, Wiley-VCH, Weinheim, 2002, pp. 1-276.

7 D. W. Pohl, W. Denk and M. Lanz, Appl. Phys. Lett., 1984, 44, 651.

8 A. Lewis and K. Liebermann, Anal. Chem., 1991, 63, 625.

9 R. Zenobi and V. Deckert, Angew. Chem. Int. Ed. Engl., 2000, 39, 1746.

10 A. Benninghoven, B. Hagenhoff and E. Niehus, Anal. Chem., 1993, 65, 630 .

11 H. Hutter in Surface and thin film analysis, ed. H. J. H. Bubert, Wiley-VCH, Weinheim, 2002, pp. 1-106.

12 F. Kollmer, R. Kamischke, R. Ostendorf, A. Schnieders, C. Y. Kim, J. W. Lee and A. Benninghoven, ed. Elsevier Science, Amsterdam, 2000, pp. 1-329.

$13 \mathrm{H}$. Bubert and H. Jenett, Surface and thin film analysis, WileyVCH, Weinheim, 2002.

14 S. F. Durrant and N. I. Ward, J. Anal. At. Spectrom., 2005, 20, 821.

15 J. S. Becker, M. Zoriy, M. Dehnhardt, C. Pickhardt and K. Zilles, J. Anal. At. Spectrom., 2005, 20, 912.

16 J. S. Becker, M. V. Zoriy, C. Pickhardt, N. Palomero-Gallagher and K. Zilles, Anal. Chem., 2005, 77, 3208.

17 D. Günther and C. A. Heinrich, J. Anal. At. Spectrom., 1999, 14, 1369.

18 J. S. Becker and H.-J. Dietze, Int. J. Mass Spectrom., 2003, 228, 127.

19 J. S. Becker, J. Anal. At. Spectrom., 2005, 20, 1173.

20 R. A. Stern, I. R. Fletcher, B. Rasmussen, N. J. McNaughton and B. J. Griffin, Int. J. Mass Spectrom., 2005, 244, 125.

21 J. S. Becker, C. Pickhardt and H.-J. Dietze, Int. J. Mass Spectrom., 2000, 203, 283.

22 J. S. Becker, A. Gorbunoff, M. Kayser, W. Pompe, U. KrauseBuchholz, G. Rödel, M. Przybylski, Verfahren und Vorrichtung zur Durchführung einer ortsaufgelösten Nano-lokal- und Verteilungsanalyse und zur quantitativen Bestimmung von Elementkonzentrationen, German Patent DE 10354787 A1, 13 November 2003, (Offenlegungsschrift: 30 June 2005).

23 M. I. Stockmann, Avtometriya, 1989, 3, 30.

24 J. I. Gersten and A. Nitzan, J. Chem. Phys., 1980, 73, 3023.

25 A. Gorbunoff, 'Laser-assisted synthesis of nanostructured materials' in Fortschr.-Ber VDI, V. Verlag, Düsseldorf, 2002, vol. 9 Nr. 357.

26 A. Gorbunoff, B. Wolf and J. Edelmann, Rev. Sci. Instrum., 1993, 64, 2393.

27 J. S. Becker, M. Zoriy, J. Su. Becker, C. Pickhardt, E. Damoc, G. Juhacz, M. Palkovits and M. Przybylski, Anal. Chem., 2005, 77, 5851.

28 J. S. Becker and H.-J. Dietze, J. Anal. At. Spectrom., 1999, 14, 1493.

29 J. S. Becker, M. Zoriy, U. Krause-Buchholz, J. Su. Becker, C. Pickhardt, M. Przybylski, W. Pompe and G. Rödel, J. Anal. At. Spectrom., 2004, 19, 1236.

30 IUPAC Isotopic Composition of the Elements 1997, J. Anal. At. Spectrom., 1999, 14, 5N.

31 J. Su. Becker, M. Zoriy, C. Pickhardt, M. Przybylski and J. S. Becker, Int. J. Mass Spectrom., 2005, 242, 135. 